\title{
Alleviation of Ultraviolet B-Induced Photodamage by Coffea arabica Extract in Human Skin Fibroblasts and Hairless Mouse Skin
}

\author{
Po-Yuan $\mathrm{Wu}^{1,2,+}{ }^{1}$, Chi-Chang Huang ${ }^{3,+}{ }^{\text {, }}$ Yin Chu ${ }^{4}$, Ya-Han Huang ${ }^{4}$, Ping Lin ${ }^{4}$, Yu-Han Liu ${ }^{4}$, \\ Kuo-Ching Wen ${ }^{4}$, Chien-Yih Lin ${ }^{5}$, Mei-Chich Hsu ${ }^{6}$ and Hsiu-Mei Chiang ${ }^{4, *}$ \\ 1 Department of Dermatology, China Medical University Hospital, Taichung 40402, Taiwan; \\ wu.poyuan@gmail.com \\ 2 School of Medicine, China Medical University, Taichung 404, Taiwan \\ 3 Graduate Institute of Sports Science, National Taiwan Sport University, Taoyuan 33301, Taiwan; \\ john5523@ntsu.edu.tw \\ 4 Department of Cosmeceutics, China Medical University, Taichung 40402, Taiwan; \\ dooo517@outlook.com (Y.C.); hedy9088723@hotmail.com (Y.-H.H.); a505351@hotmail.com (P.L.); \\ lesley456987@yahoo.com.tw (Y.-H.L.); kcwen0520@mail.cmu.edu.tw (K.-C.W.) \\ 5 Department of Biotechnology, Asia University, Taichung 41354, Taiwan; yihlin@asia.edu.tw \\ 6 Department of Sports Medicine, Kaohsiung Medical University, Kaohsiung 80708, Taiwan; \\ meichich@kmu.edu.tw \\ * Correspondence: hmchiang@mail.cmu.edu.tw; Tel.: +886-4-22053366 (ext. 5302); Fax: +886-4-22078083 \\ + These authors contributed equally to this work.
}

Academic Editor: Maurizio Battino

Received: 12 February 2017; Accepted: 26 March 2017; Published: 7 April 2017

\begin{abstract}
Coffea arabica extract (CAE) containing $48.3 \pm 0.4 \mathrm{mg} / \mathrm{g}$ of chlorogenic acid and a trace amount of caffeic acid was found to alleviate photoaging activity in human skin fibroblasts. In this study, polyphenol-rich CAE was investigated for its antioxidant and antiinflammatory properties, as well as for its capability to alleviate ultraviolet B (UVB)-induced photodamage in BALB/c hairless mice. The results indicated that $500 \mu \mathrm{g} / \mathrm{mL}$ of CAE exhibited a reducing power of $94.7 \%$, ferrous ion chelating activity of $46.4 \%$, and hydroxyl radical scavenging activity of $20.3 \%$. The CAE dose dependently reduced UVB-induced reactive oxygen species (ROS) generation in fibroblasts. Furthermore, CAE inhibited the UVB-induced expression of cyclooxygenase- 2 and $p$-inhibitor $\mathrm{kB}$, and the translocation of nuclear factor-kappa $\mathrm{B}(\mathrm{NF}-\mathrm{kB})$ to the nucleus of fibroblasts. In addition, CAE alleviated UVB-induced photoaging and photodamage in BALB/c hairless mice by restoring the collagen content and reduced UVB-induced epidermal hyperplasia. CAE also inhibited UVB-induced NF- $\mathrm{kB}$, interleukin-6, and matrix metalloproteinase-1 expression in the hairless mouse skin. The results indicated that CAE exhibits antiphotodamage activity by inhibiting UV-induced oxidative stress and inflammation. Therefore, CAE is a candidate for use in antioxidant, antiinflammatory, and antiphotodamage products.
\end{abstract}

Keywords: Coffea arabica; photodamage; antioxidant; inflammatory; nuclear factor-kappa B (NF- $\mathrm{kB}$ ); inhibitor $\mathrm{kB}(\mathrm{I} \kappa \mathrm{B})$

\section{Introduction}

In recent years, the incidence of skin cancer has increased, possibly because of the depletion of the ozone layer, causing an increased exposure to solar radiation, and the use of ultraviolet (UV) tanning beds [1]. Skin aging depends on intrinsic factors, such as genetics and hormones, and extrinsic factors, such as UV radiation and environmental pollutants. UV radiation is the most crucial factor for skin 
aging, or photoaging, which is characterized by wrinkling, rough skin, and hyperpigmentation [2,3]. UVB irradiation stimulates inflammation and reactive oxygen species (ROS) formation, promoting aging-related signal transduction resulting in skin damage and photoaging. Collagen is one of the components of the extracellular matrix, which is synthesized by fibroblasts in the dermis, and contributes to skin strength and resilience [4,5].

UV irradiation produces peroxynitrite and ROS [6]. ROS upregulate cyclooxygenase (COX)-2 expression to stimulate inflammation, which then cause skin erythema and sunburn [7-9]. UV exposure generates prostaglandin E2 and leukotrienes that lead to erythema, edema, and inflammation [10]. Under normal conditions, nuclear factor-kappa B (NF- $\kappa B$ ) binds to inhibitor $\kappa B$ (I $\kappa B$ ) and forms an inactive complex in the cytoplasm [11,12]. When stimulated by UV irradiation, the ubiquitination of I $\kappa \mathrm{B}$ triggers the translocation of NF- $\kappa B$ into the nucleus, which further increases the production of matrix metalloproteinase (MMP)-1, and subsequently, the degradation of collagen [12-14]. In addition, interleukins (ILs) and nuclear factor-kappa B (NF- $\mathrm{kB}$ ) may induce COX-2 expression in the skin, causing skin photodamage [15].

Recently, increasing attention has been focused on the development of natural or plant products for use as antioxidants, antiinflammatory agents, and immunomodulatory agents, to prevent age-related disorders [16-19]. The application of antioxidants to the skin surface protects the skin from oxidative damage and photodamage for a long time [19-21]. Many plant antioxidants also exhibit antiinflammatory activity and can be used to alleviate oxidative stress-induced damage, such as photodamage and skin cancer [22-26]. Coffee is one of the most popular beverages in the world and a major source of dietary antioxidants; it has also been suggested to inhibit inflammation and scavenge free radicals $[27,28]$. Furthermore, coffee bean extract inhibits the formation of lipid peroxide and superoxide free radicals $[29,30]$. In a clinical study, a cream prepared from coffee berry extract was observed to reduce wrinkles and hyperpigmentation of the human skin, and improve the skin appearance [31]. In addition, coffee berry extract upregulated the gene and protein levels of collagens and growth factors, and downregulated the gene expression of MMPs in human cultured fibroblasts [31]. In our previous study, Coffea arabica extract (CAE) obtained from the leaves of $C$. arabica showed high 1,1-diphenyl-2-picrylhydrazyl (DPPH) radical scavenging activity and prevented 2,2'-azobis (2-amidinopropane) dihydrochloride (AAPH) radical-induced hemolysis of erythrocytes [32]. Furthermore, CAE promoted type I procollagen expression, suppressed MMP expression, and inhibited MAP kinase activation in human foreskin fibroblast (Hs68) cells [32]. Our previous study and the aforementioned studies indicate that CAE is a candidate for use in antiaging and antiphotoaging products.

This study investigated the potential of CAE to counteract UVB irradiation-induced oxidative stress, inflammation, and photodamage in fibroblasts and hairless mice, and elucidated the associated mechanisms.

\section{Results}

\subsection{Antioxidant Activity of Coffea arabica Extract (CAE)}

The reducing capability of CAE and ascorbic acid (positive control) observed in the present study is shown in Figure 1. CAE exhibited a potent reducing activity, and the reducing activity of $50 \mu \mathrm{g} / \mathrm{mL}$ of CAE was $80 \%$. Furthermore, the reducing activity of $100 \mu \mathrm{g} / \mathrm{mL}$ of CAE was similar to that of ascorbic acid at the same concentration. Figure 2 shows the chelating activity of CAE and EDTA $(500 \mu \mathrm{g} / \mathrm{mL}$, the positive control). The metal chelating activity of $500 \mu \mathrm{g} / \mathrm{mL}$ of CAE was $46.4 \% \pm 2.0 \%$ and that of EDTA at the same concentration was $74.5 \% \pm 3.1 \%$. 


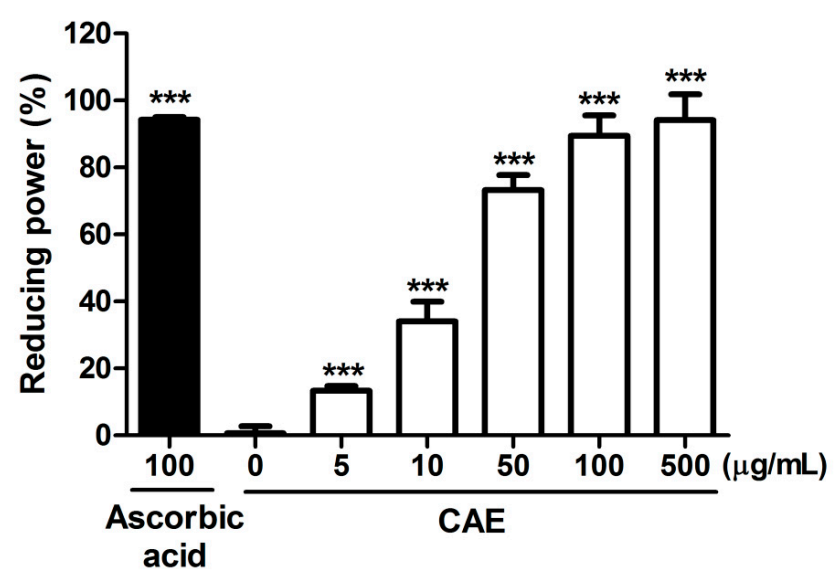

Figure 1. Reducing capability of CAE. Ascorbic acid $(100 \mu \mathrm{g} / \mathrm{mL})$ was used as the positive control. The reducing capability of CAE at concentrations above $100 \mu \mathrm{g} / \mathrm{mL}$ was similar to that of ascorbic acid. Significant difference versus control in each experiment: ${ }^{* * *}, p<0.001$.

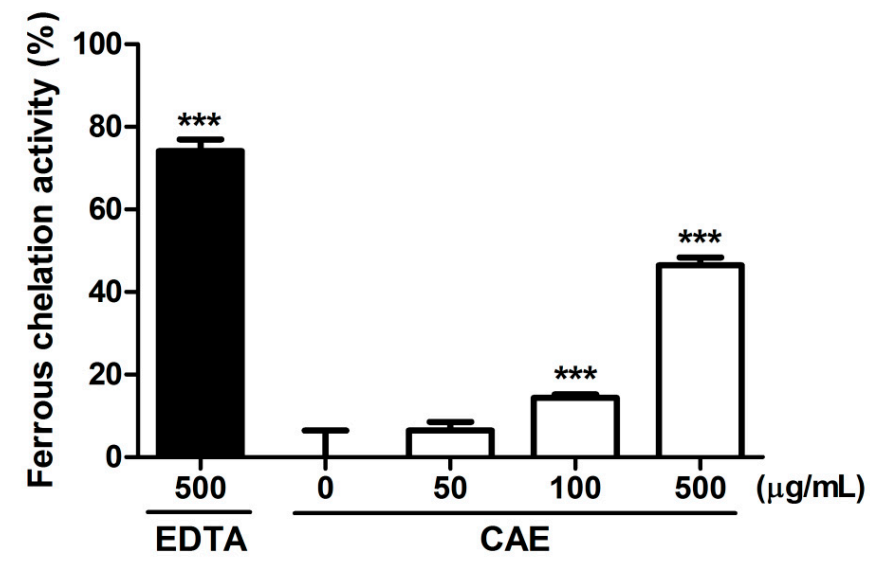

Figure 2. Ferrous ion chelating activity of CAE. EDTA $(500 \mu \mathrm{g} / \mathrm{mL})$ was applied as the positive control. A significant difference between this activity and that of the untreated $(0 \mu \mathrm{g} / \mathrm{mL}$ CAE) group could be observed. Significant difference versus control in each experiment: ${ }^{* * *}, p<0.001$.

The scavenging capability of CAE was evaluated for various free radicals. The hydroxyl radical scavenging activity of CAE and the positive control (mannitol) is presented in Figure 3. The hydroxyl radical scavenging activity of $50 \mu \mathrm{g} / \mathrm{mL}$ of CAE was $72.7 \% \pm 6.6 \%$, and that of $2500 \mu \mathrm{g} / \mathrm{mL}$ of mannitol was $57.4 \% \pm 4.8 \%$. The superoxide anion scavenging activity of CAE is shown in Figure 4 . The superoxide anion scavenging activity of dibutyl hydroxy toluene (BHT, positive control) was $55.9 \% \pm 6.7 \%$. The superoxide anion scavenging activity of $1 \mu \mathrm{g} / \mathrm{mL}$ of CAE was similar to that of $250 \mu \mathrm{g} / \mathrm{mL}$ of BHT (Figure 4). In addition, the peroxide scavenging activity of CAE is shown in Figure 5 . The peroxide scavenging activity of $50,100,500$, and $1000 \mu \mathrm{g} / \mathrm{mL}$ of CAE was $18.8 \% \pm 7.5 \%$, $14.9 \% \pm 3.0 \%, 105.4 \% \pm 1.9 \%$, and $115.0 \% \pm 1.2 \%$, respectively. These results indicate that CAE exhibits a potent free radical scavenging activity. 


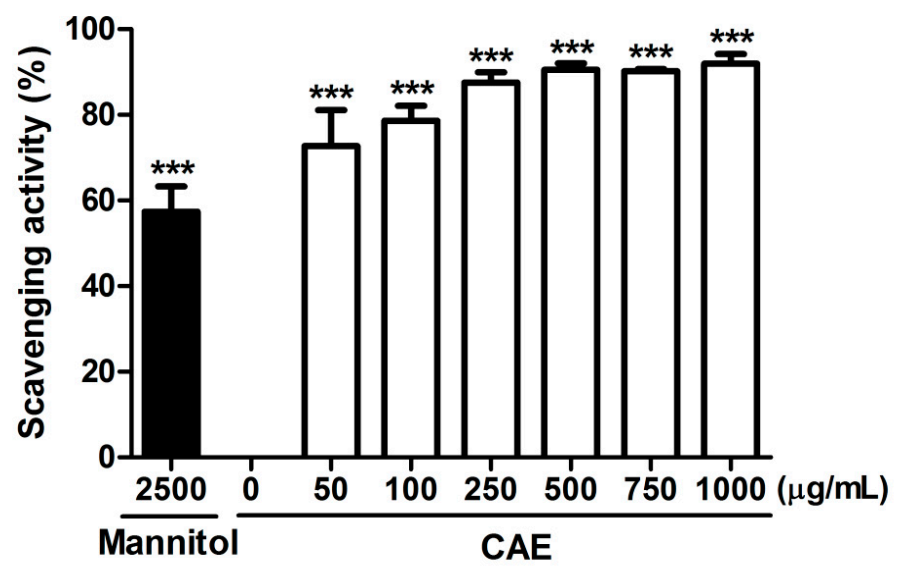

Figure 3. Hydroxyl radical scavenging activity (\%) of CAE. Mannitol $(2500 \mu \mathrm{g} / \mathrm{mL})$ was used as the positive control. CAE exhibited powerful hydroxyl radical scavenging activity. Significant difference versus control in each experiment: ${ }^{* *}, p<0.001$.

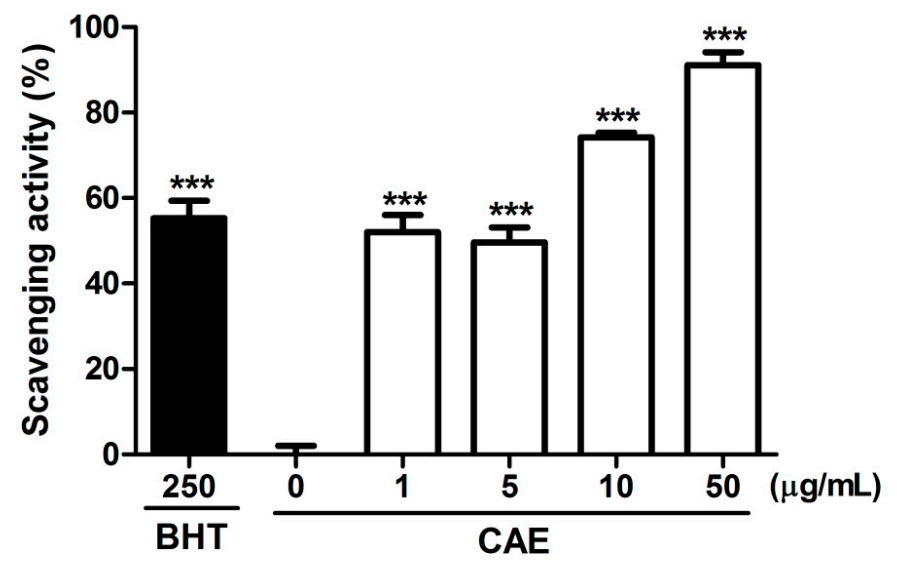

Figure 4. Superoxide anion scavenging activity (\%) of CAE. BHT $(250 \mu \mathrm{g} / \mathrm{mL})$ was used as the positive control. The superoxide anion scavenging activity of 1 and $5 \mu \mathrm{g} / \mathrm{mL}$ CAE was similar to that of BHT. Significant difference versus control in each experiment: ${ }^{* *}, p<0.001$.

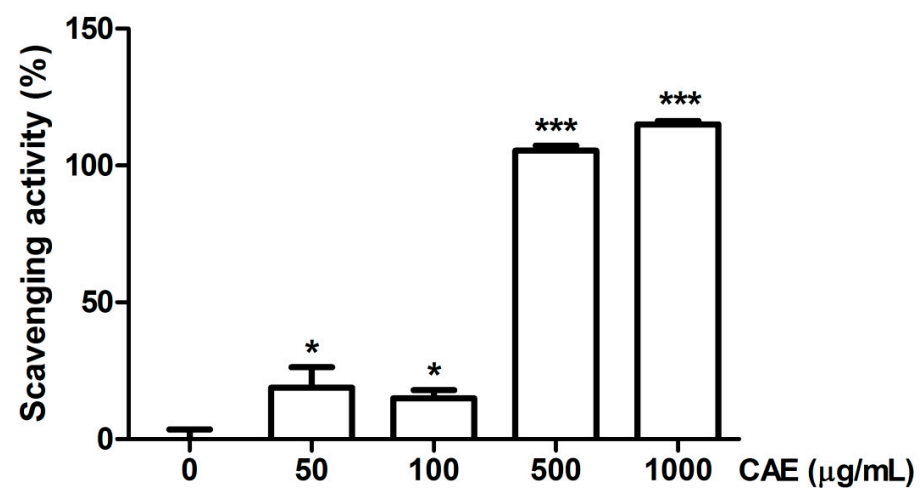

Figure 5. Hydrogen peroxide scavenging activity (\%) of CAE. A significant difference between this activity and that of the untreated $(0 \mu \mathrm{g} / \mathrm{mL}$ CAE) group can be observed. Significant difference versus control in each experiment: ${ }^{*}, p<0.05,{ }^{* * *}, p<0.001$. 


\subsection{CAE Inhibited ROS Generation in Human Skin Fibroblasts}

UV-induced ROS generation plays a crucial role in the photoaging of skin [33]. The intracellular ROS generation was assayed through $2^{\prime}, 7^{\prime}$-dichlorofluorescein diacetate (DCFDA) staining and fluorescence microscopy. Various CAE concentrations $(1-50 \mu \mathrm{g} / \mathrm{mL})$ dose dependently inhibited ROS generation in fibroblasts (Figure 6). In addition, UV irradiation inhibited catalase (CAT) activity, and postirradiation treatment with CAE enhanced CAT activity in human skin fibroblasts (Figure 7).

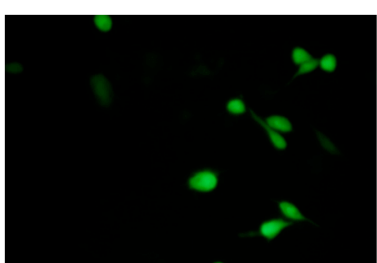

Control

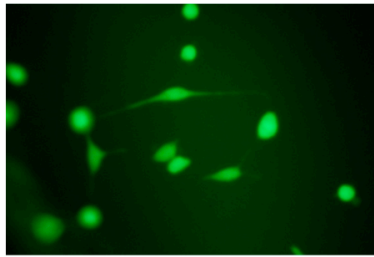

CAE $5 \mathrm{\mu g} / \mathbf{m L}$

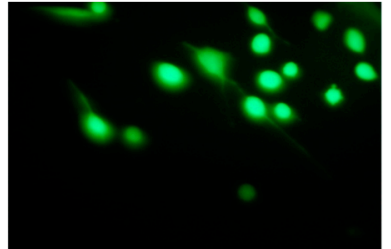

UV $80 \mathrm{~mJ} / \mathrm{cm}^{2}$

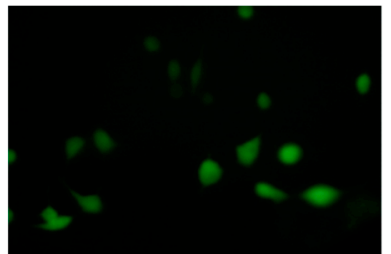

CAE $10 \mu \mathrm{g} / \mathrm{mL}$

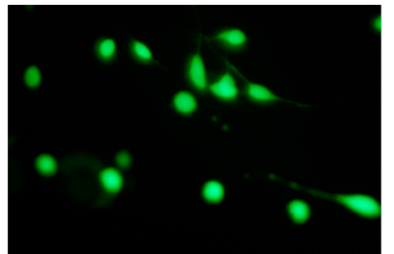

CAE $1 \mu \mathrm{g} / \mathbf{m L}$

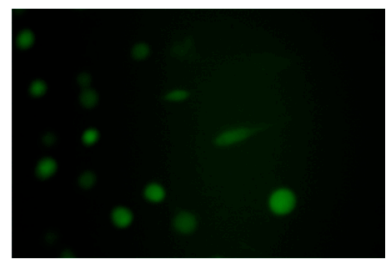

CAE $50 \mu \mathrm{g} / \mathbf{m L}$

Figure 6. Examination of CAE inhibition of intracellular ROS generation in human skin fibroblasts by using a DCFH-DA assay (magnification factor: 200×). UVB irradiation increased ROS generation, whereas CAE inhibited ROS generation.

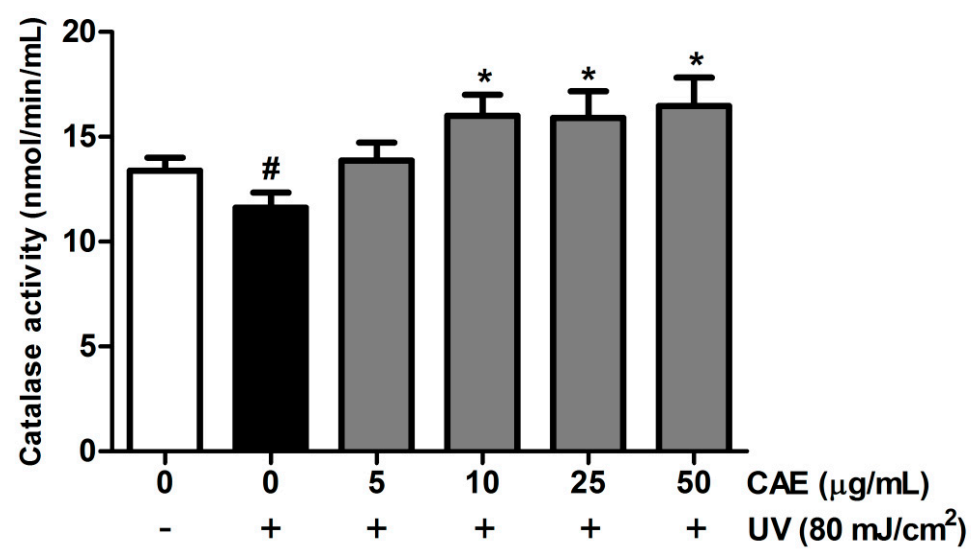

Figure 7. Effects of CAE on CAT activity in human skin fibroblasts. UVB irradiation inhibited CAT activity, whereas CAE treatment reversed the effect. Significant difference versus control: \#, $p<0.05$; significant difference versus the UVB-induced group: ${ }^{*}, p<0.05$.

\subsection{Effect of CAE on UVB-Induced Inflammation}

UV-induced inflammation contributes to the chronological and premature aging of the skin [34]. The results of this study showed that the COX-2 level in UVB-exposed fibroblasts was 1.5-fold compared with that in the control cells (Figure 8). CAE treatment $(5-50 \mu \mathrm{g} / \mathrm{mL}$ ) inhibited the UVB-induced upregulation of COX-2, and this effect was substantial when the concentration of CAE exceeded $25 \mu \mathrm{M}$ (Figure 8). 

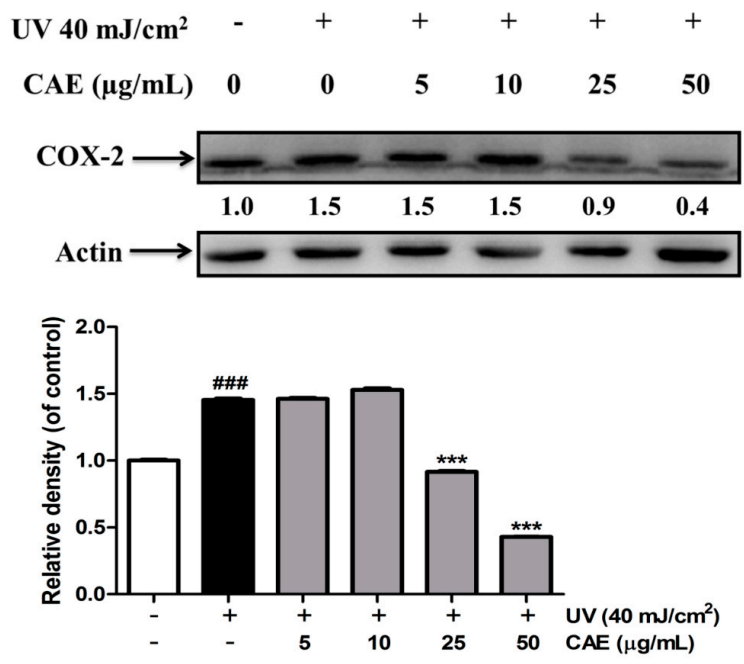

Figure 8. Effects of CAE on UVB-induced COX-2 expression in human skin fibroblasts. Significant difference versus control: \#\#, $p<0.001$; significant difference versus the UVB-induced group: ${ }^{* * *}, p<0.001$.

As shown in Figure 9, $p$-IкB $\alpha$ expression increased by 1.3-fold after UVB exposure, and CAE treatment considerably reduced $p$-I $\kappa \mathrm{B} \alpha$ expression. In addition, CAE considerably increased the I $\mathrm{B} \alpha$ level (from 0.7- to 0.9-fold; Figure 9). In this study, the NF- $\kappa$ B immunofluorescence staining assay in fibroblast cells was applied, to determine the level of NF- $k B$ activation. Figure 10 shows that the translocation of NF- $\mathrm{KB}$ from the cytoplasm to the nucleus increased after UVB irradiation, whereas the translocation was inhibited after CAE treatment. The results of the immunofluorescence staining assay were consistent with $\mathrm{I} \kappa \mathrm{B} / p$-I $\kappa \mathrm{B} \alpha$ expression. The results of the immunoblot analysis indicated that the protein level of $\mathrm{I} \kappa \mathrm{B} \alpha$ was inhibited by ubiquitination following UVB irradiation, whereas $p$-IкB $\alpha$ expression was elevated (Figure 9). Subsequently, NF- $\kappa \mathrm{B}$ translocated to the nucleus, causing an inflammatory response. However, CAE treatment inhibited the UVB-activated I $\mathrm{KB} / \mathrm{NF}-\kappa \mathrm{B}$ signaling cascade, to ameliorate the inflammatory response.
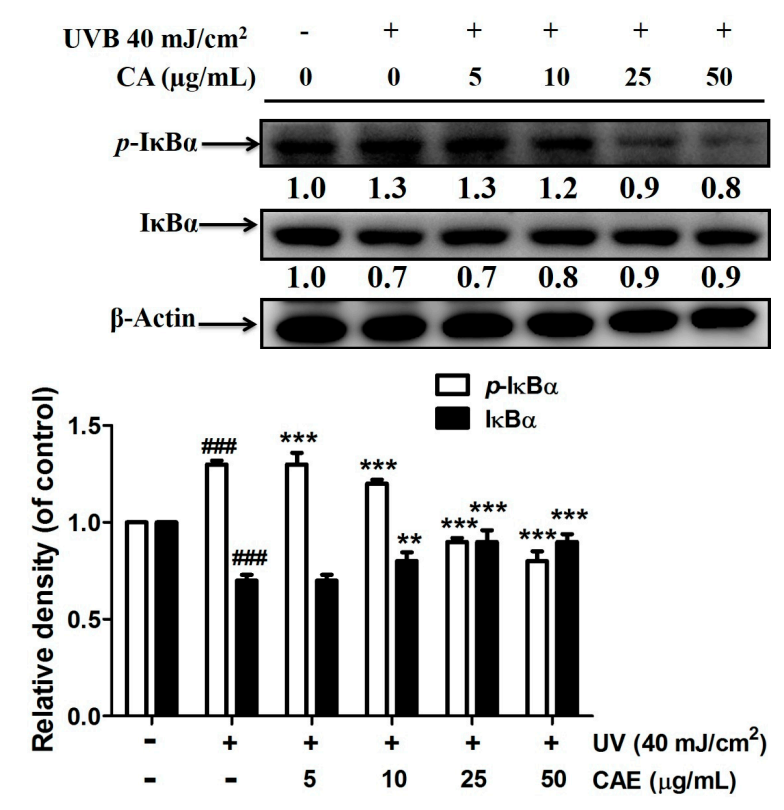

Figure 9. Effect of CAE on UVB-mediated $p-\mathrm{I} \kappa \mathrm{B} \alpha$ and $\mathrm{I} \kappa \mathrm{B} \alpha$ expression in human skin fibroblasts. Significant difference versus control: \#\#\#, $p<0.001$; significant difference versus the UVB-induced group: ${ }^{* *}, p<0.01,{ }^{* * *}, p<0.001$. 


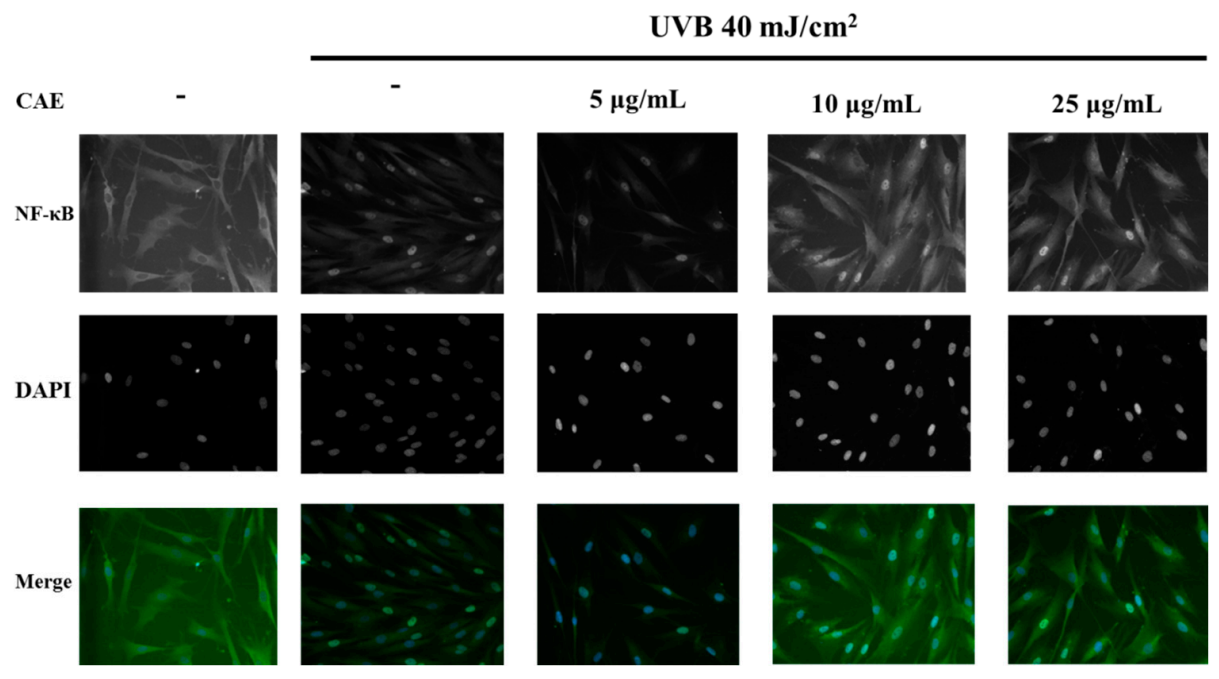

Figure 10. Effects of CAE on UVB-induced activation of NF- $\kappa B$ in human skin fibroblasts (magnification factor: $200 \times$ ). UVB promoted the translocation of NF- $K B$ in the nucleus and CAE inhibited this effect.

\subsection{Antiphotoaging Activity of CAE on UVB-Irradiated Hairless Mouse Skin}

After the 10-week experiment, the body weights of mice did not differ substantially in all the groups (data not shown). The $\mathrm{a}^{*}$ value is an index of erythema and shows the inflammation degree in the skin. The $\mathrm{a}^{*}$ values increased after UVB treatment, indicating that UVB induced erythema and inflammation of the skin (Figure 11). CAE treatment considerably reduced the $\mathrm{a}^{*}$ values of the skin detected in the ninth and tenth week, and the $\mathrm{a}^{*}$ values of CAE were similar to those of the normal group in the tenth week. These results suggest that CAE ameliorated UVB-induced inflammation and erythema.

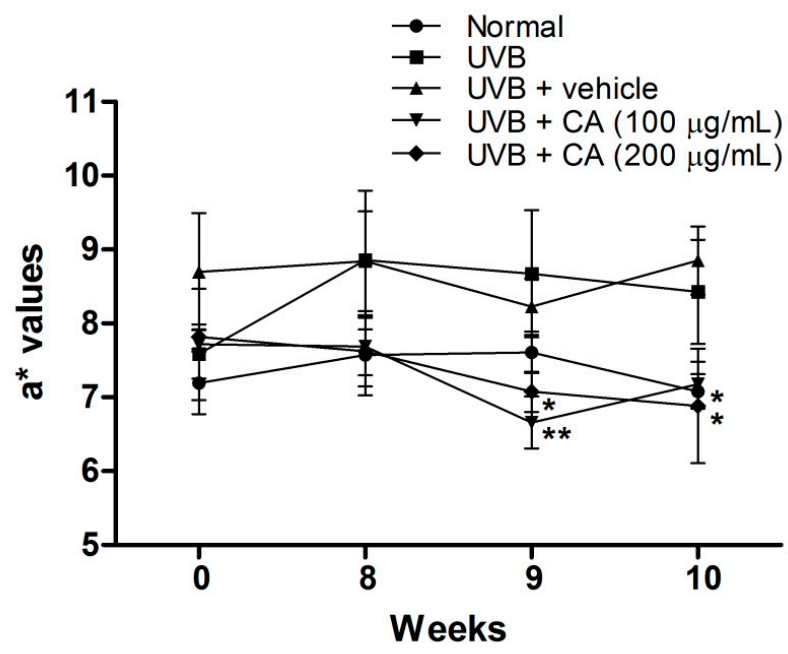

Figure 11. Effects of CAE on $\mathrm{a}^{*}$ values in UVB-irradiated hairless mice in the tenth week. Significant difference versus the UVB-induced group: ${ }^{*}, p<0.05,{ }^{* *}, p<0.01$.

The measurements of transepidermal water loss (TEWL) are useful for understanding the skin damage caused by some chemicals, pathological conditions, or environmental conditions, because the TEWL rate increases in proportion to the level of skin damage [35]. In the current study, UVB exposure of mice considerably enhanced the TEWL. The TEWL decreased after CAE application to hairless mice for 10 weeks (Figure 12), indicating that CAE did not cause skin toxicity or damage. In contrast, CAE appeared to protect the skin. 


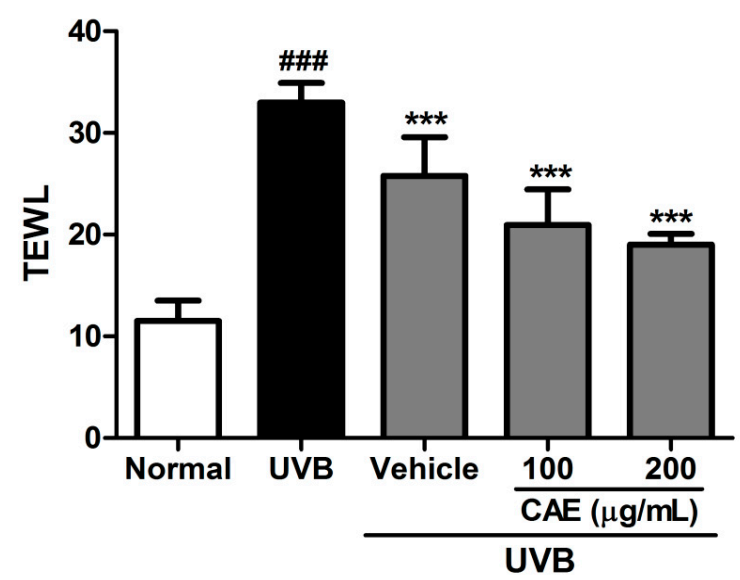

Figure 12. Effects of CAE on TEWL in chronic UVB-irradiated hairless mice. Significant difference versus control: \#\#\#, $p<0.001$; significant difference versus the UVB-induced group: ${ }^{* * *}, p<0.001$.

As shown in Figure 13, the formation of wrinkles was observed in the dorsal region in the UVB-exposed group. The topical application of CAE $(100$ and $200 \mu \mathrm{g} / \mathrm{mL})$ reduced the wrinkle formation (Figure 13).

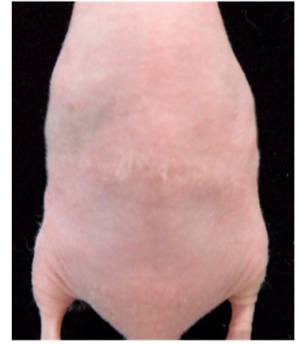

Normal

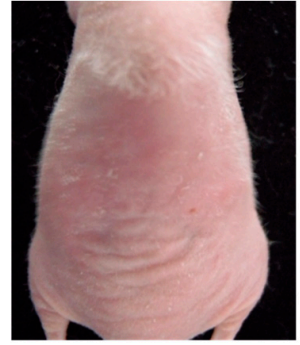

UVB

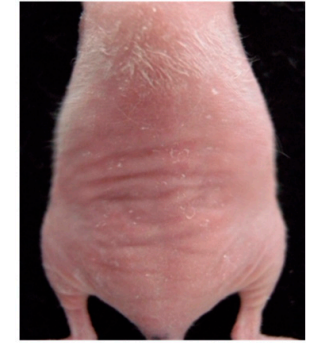

UVB + vehicle
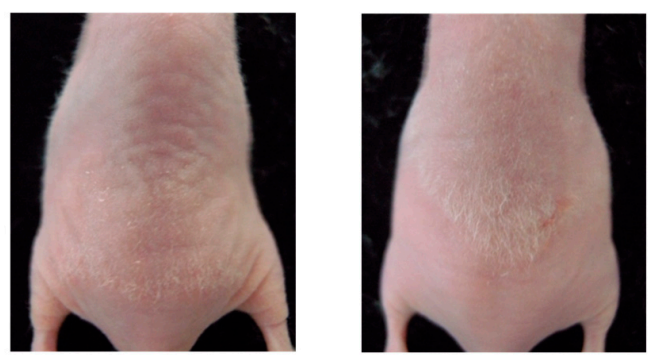

UVB + CAE $100 \mu \mathrm{g} / \mathrm{mL} \quad$ UVB + CAE $200 \mu \mathrm{g} / \mathrm{mL}$

Figure 13. Photographs of wrinkles induced by UVB irradiation and the effect of topical application of CAE.

The activity of CAE on the lesions, thickness, and collagen density of the skin in hairless mice after UVB irradiation was determined through histological examination. As shown in Figures 14 and 15, the epidermal thicknesses of the UVB-exposed group, $100 \mu \mathrm{g} / \mathrm{mL}$ CAE-treated group, and $200 \mu \mathrm{g} / \mathrm{mL}$ CAE-treated group, were $84.6 \pm 1.0,41.5 \pm 0.2$, and $35.4 \pm 0.9 \mu \mathrm{m}$, respectively. UVB irradiation resulted in a significant increase in the skin thickness compared with that of normal mice; however, the increase in the epidermal thickness caused by UVB irradiation decreased significantly after the topical application of CAE (Figures 14 and 15). Masson's trichrome staining of the dorsal skin showed that the collagen content decreased considerably after UVB exposure. The topical application of CAE increased the collagen amount in the dermis of BALB/c hairless mice (Figure 16). 


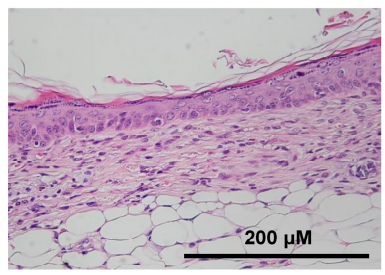

Normal

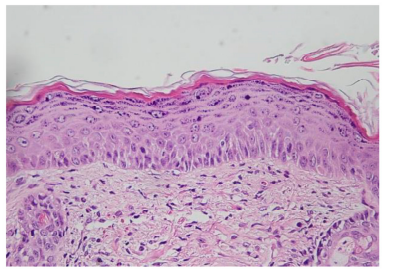

UVB

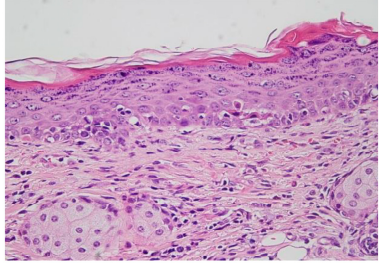

UVB + vehicle
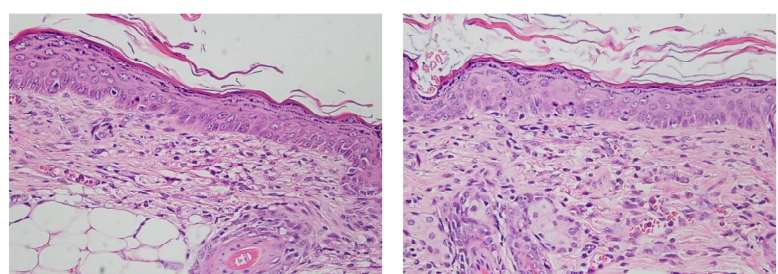

UVB + CAE $100 \mu \mathrm{g} / \mathrm{mL} \quad$ UVB + CAE $200 \mu \mathrm{g} / \mathrm{mL}$

Figure 14. Light micrographs of the histological sections of hairless mice stained with $\mathrm{H} \& \mathrm{E}$.

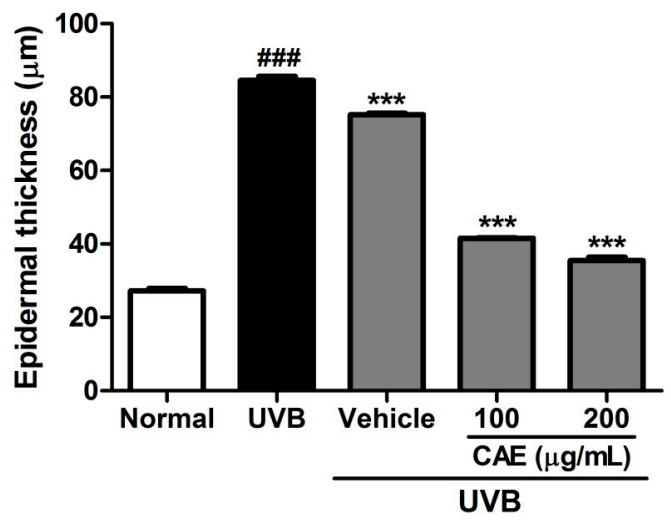

Figure 15. Skin thickness of hairless mice after CAE treatment. Significant difference versus the normal group: \#\#\#, $p<0.001$; significant difference versus the UVB-induced group: ${ }^{* * *}, p<0.001$.

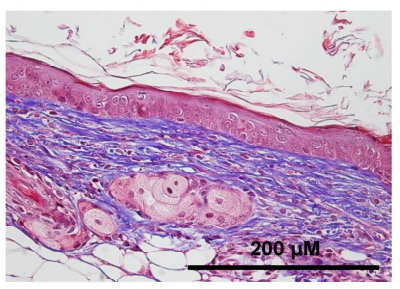

Normal

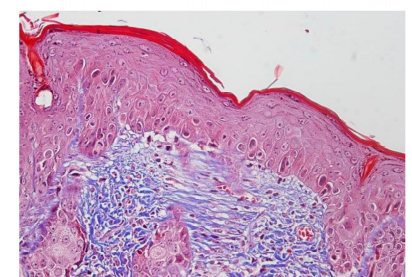

UVB

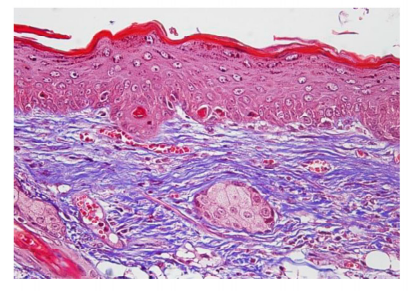

UVB + vehicle
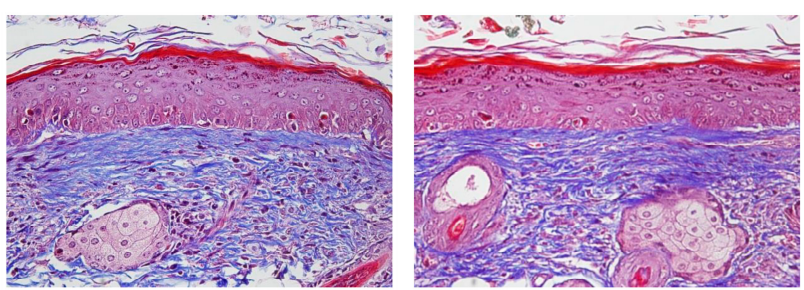

UVB + CAE $100 \mu \mathrm{g} / \mathrm{mL} \quad$ UVB + CAE $200 \mu \mathrm{g} / \mathrm{mL}$

Figure 16. Light micrographs of histological sections of hairless mice stained with Masson's trichrome. Collagen fibers were stained blue. UVB exposure reduced the collagen content in the mouse skin dermis and CAE treatment restored the collagen content. 
2.5. CAE Inhibited MMP-1, iNOS, IL-6, and NF- $k B$ Levels in UVB-Exposed Hairless Mouse Dermis

UVB-induced MMP-1 overexpression causes collagen degradation in the skin. As presented in Figure 17, MMP-1 expression increased after UVB irradiation, and CAE treatment reduced MMP-1 expression.

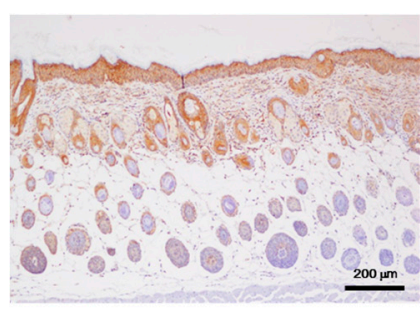

Normal

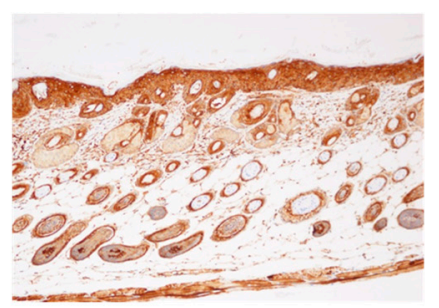

UVB

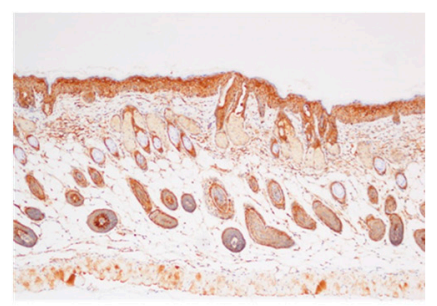

UVB + vehicle
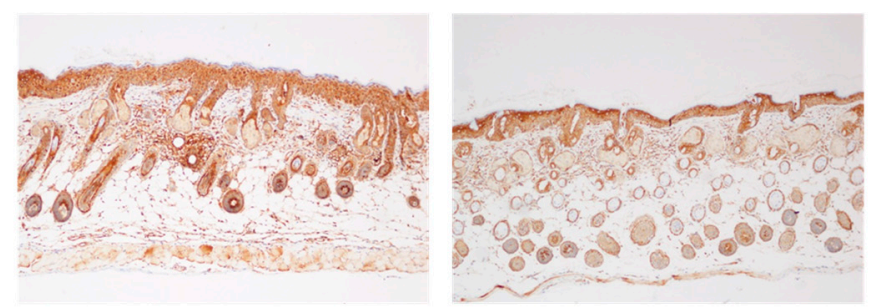

\section{UVB + CAE $100 \mu \mathrm{g} / \mathrm{mL} \quad$ UVB + CAE $200 \mu \mathrm{g} / \mathrm{mL}$}

Figure 17. Immunohistological staining for MMP-1 in the hairless mouse skin after UVB exposure and CAE treatment. MMP-1 expression increased after UVB irradiation in the mouse skin, whereas CAE treatment inhibited the effect.

UVB upregulates inflammatory cytokines and the related factors, causing skin damage. Figures 18-20 illustrate that UVB irradiation induced iNOS, IL-6, and NF- $\mathrm{kB}$ expression in the mouse skin, whereas the topical application of CAE significantly inhibited UVB-induced inflammation.

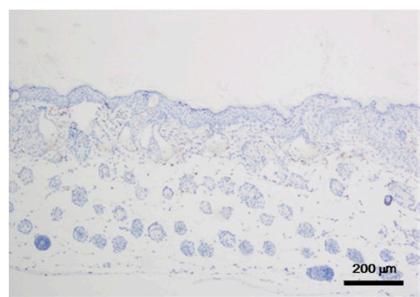

Normal

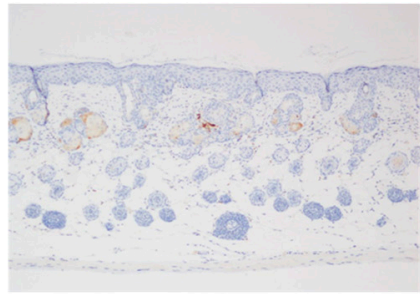

UVB

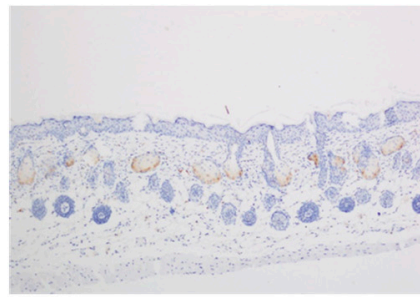

UVB + vehicle
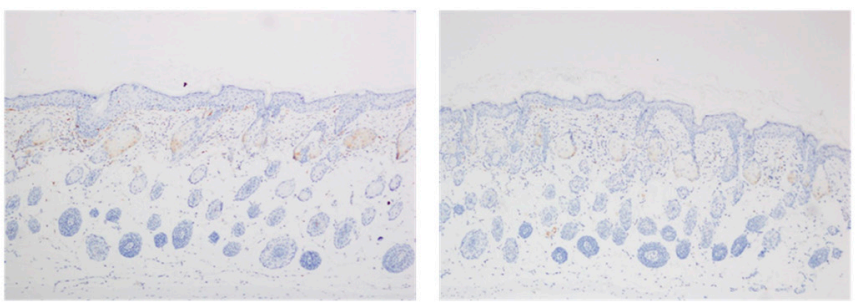

UVB + CAE $100 \mu \mathrm{g} / \mathrm{mL} \quad$ UVB + CAE $200 \mu \mathrm{g} / \mathrm{mL}$

Figure 18. Immunohistological staining for iNOS in the hairless mouse skin after UVB exposure and CAE treatment. 


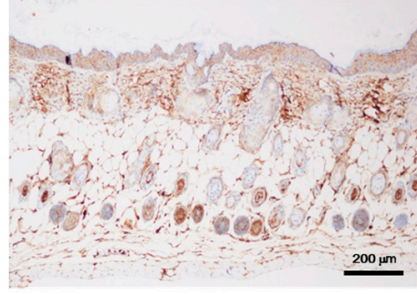

Normal

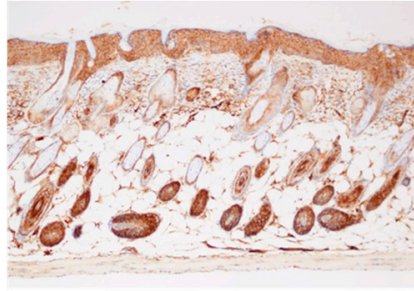

UVB

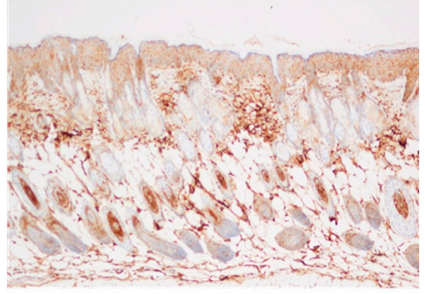

UVB + vehicle
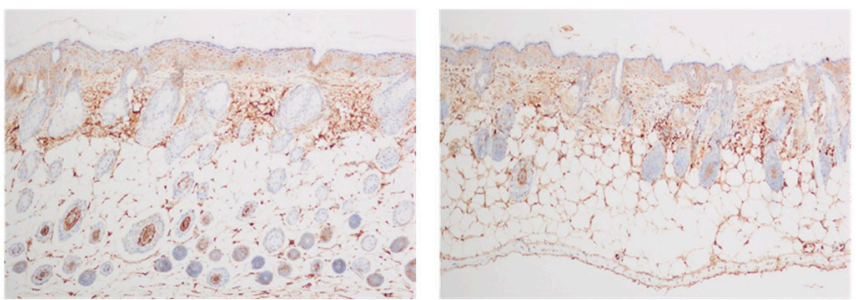

\section{UVB + CAE $100 \mu \mathrm{g} / \mathrm{mL} \quad$ UVB + CAE $200 \mu \mathrm{g} / \mathrm{mL}$}

Figure 19. Immunohistological staining for IL-6 in the hairless mouse skin after UVB exposure and CAE treatment.

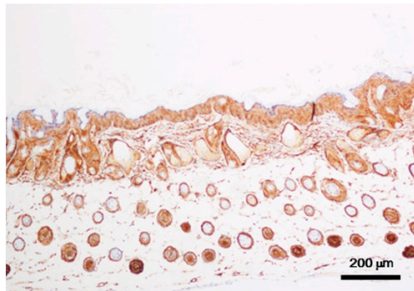

Normal

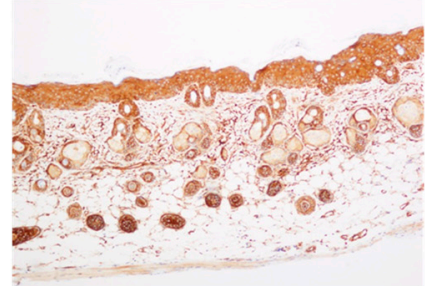

UVB

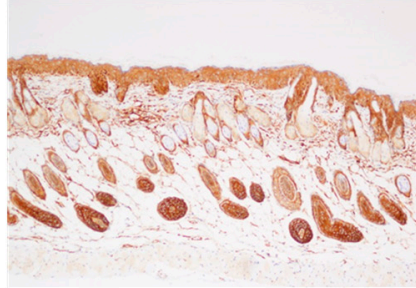

UVB + vehicle
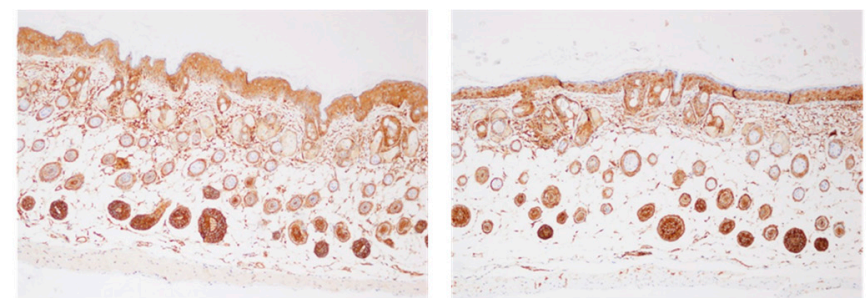

\section{UVB + CAE $100 \mu \mathrm{g} / \mathrm{mL} \quad$ UVB + CAE $200 \mu \mathrm{g} / \mathrm{mL}$}

Figure 20. Immunohistological staining for NF- $\kappa B$ in the hairless mouse skin after UVB exposure and CAE treatment.

\section{Discussion}

Oxidation is the major cause of aging, and the biochemical reaction associated with the normal metabolic process often produces free radicals and ROS. Transition metal ions, including $\mathrm{Fe}^{2+}$ and $\mathrm{Cu}^{2+}$, participate in various oxidation reactions and catalyze hydroxyl radical formation [36]. Hydroxyl radicals are the most active ROS and rapidly react with biomembranes and biomolecules, causing severe damage. Metal ion chelation indirectly contributes to oxidative stress and ameliorates the process of skin aging. Ferrous chelation exhibits crucial antioxidant activity by inhibiting metal-catalyzed oxidation. In recent decades, natural products and plants have gained attention as photoprotective agents and may be added to skin care products for topical applications [19]. In our previous study, CAE with a rich polyphenol content exhibited DPPH scavenging activity and prevented erythrocytes from hemolysis induced by AAPH [32]. The results of this study revealed that 
the reducing power of CAE is similar to that of ascorbic acid. CAE chelated $46.4 \%$ of free $\mathrm{Fe}^{2+}$ and exhibited high scavenging activity for hydroxyl radicals, superoxide, and peroxide. Furthermore, the results of the free radical scavenging assays performed in this study indicated that CAE is a powerful antioxidant. CAE contains abundant polyphenols that can quench lipid peroxyl radicals and chelate iron in fibroblasts, thus inhibiting the initiation of lipid peroxidation [37]. Coffee bean extract scavenges free radicals and inhibits lipoxygenase activity [38]. The results reported in the present study are consistent with those reported in the literature.

A high concentration of ROS triggered by UV irradiation can cause various aging-related disorders, such as atherosclerosis, skin aging, and cancer [39]. UV exposure can deplete the endogenous oxidative stress defense system, resulting in ROS accumulation that can induce lipid peroxidation and macromolecule damage, especially in the skin. In addition, UV irradiation increases ROS generation and alters the functions and structures of proteins and genes, resulting in skin damage $[2,33,40]$. CAE, which inhibits ROS formation by UVB and acts as a UV absorber, can be used in photoprotective agents. CAE also increases CAT activity, which is depleted by UVB. UV irradiation activates MMPs to promote degradation and reduce collagen production in the skin, resulting in wrinkle formation and sagging skin [41,42]. CAE treatment can block UVB-induced collagen degradation in human skin fibroblasts [32]. The topical application of natural products with high antioxidant and antiinflammatory activity may ameliorate UV-induced photoaging [23,43]. In a previous study, the topical application of a cream containing coffee berry extract reduced wrinkle formation on the skin [31]. In addition, coffee berry extract inhibited MMP expression and stimulated collagen and growth factor levels [31]. The results of this study demonstrate that coffee leaf extract exhibits potent antioxidant activity and reduces wrinkle formation after UVB exposure.

Studies have demonstrated that the levels and expressions of proinflammatory factors, such as COX-2 and ILs, are induced by UVB exposure [7,9]. In the current study, CAE reduced UVB-induced COX-2 expression in fibroblasts and the hairless mouse skin, preventing the skin from photodamage. $\mathrm{NF}-\mathrm{kB} / \mathrm{p} 65$ is regulated by the phosphorylation of MAP kinases [44]. The upregulated ILs and NF- $\mathrm{B}$ may stimulate the activity of COX-2 in keratinocytes and fibroblasts in the aged skin [15]. In our previous study, CAE treatment inhibited the phosphorylation of MAP kinases [32], which may inhibit the activation of NF- $\mathrm{kB}$. NF- $\mathrm{kB}$ is bound to I $\mathrm{kBs}$, a family of inhibitory proteins, and is present in the cytoplasm. The phosphorylation and degradation of IKB results in the translocation of NF- $\mathrm{KB}$ to the nucleus, which induces the transcription of proinflammatory mediators such as iNOS, ILs, and COX-2 [45]. The results indicated that CAE reduced the UVB-induced activation and translocation of NF- $\kappa B$ by $I \kappa B \alpha$ protein degradation in fibroblasts. Coffee consumption is related to a lower risk of mortality and cardiovascular disease because of the antiinflammatory activity of coffee [27].

C. arabica contains chlorogenic acid, caffeine, cafestol, and caffeic acid [32,46,47]. The results of our previous study indicated that the total phenolic content of CAE was $26.7 \pm 1.6 \mu \mathrm{g} / \mathrm{mg}$, and CAE contained $48.3 \pm 0.4 \mathrm{mg} / \mathrm{g}$ of chlorogenic acid and a small amount of caffeic acid [32]. Chlorogenic acid could inhibit the activation of inflammatory factors, such as COX-2, NF- $\mathrm{kB}$, and iNOS, in the mouse skin after 12-O-tetradecanoylphorbol-13-acetate treatment and prevent skin cancer [48]. In addition, chlorogenic acid protects humans from the oxidative damage of macromolecules such as proteins and lipids [49]. Caffeic acid inhibited UVB-induced MMP-1 and -9 expression, and chlorogenic acid suppressed MMP-1 and -3 overexpression [32]. Therefore, polyphenols, chlorogenic acid, and caffeic acid may contribute to the antiinflammatory and antiphotodamage activity of CAE.

\section{Materials and Methods}

\subsection{Chemicals and Materials}

CAE with $48.3 \pm 0.4 \mathrm{mg} / \mathrm{g}$ of chlorogenic acid and a trace amount of caffeic acid was prepared as described in a previous study [32]. The Bradford reagent for protein quantitation was obtained from Bio-Rad Laboratories (Berkeley, CA, USA). Fetal bovine serum (FBS), Dulbecco's 
modified Eagle's medium (DMEM), trypsin-ethylenediaminetetraacetic acid, and reagents for cell culture were purchased from Gibco, Invitrogen (Carlsbad, CA, USA). $\mathrm{AlCl}_{3} \cdot 6 \mathrm{H}_{2} \mathrm{O}, \mathrm{DCFDA}$, dimethyl sulfoxide, calcium chloride, $\mathrm{CH}_{3} \mathrm{COOK}$, DL-dithiothreitol, $\mathrm{FeCl}_{2}, \mathrm{FeCl}_{3}$, 2-thiobarbituric acid, 3-(2-pyridyl)-5,6-diphenyl-1,2,3-triazine-4' $4^{\prime}$ "-disulfonic acid sodium salt, deoxyribose, sodium nitrite, trichloroacetic acid (TCA), and other reagents were obtained from Sigma-Aldrich (St. Louis, MO, USA). The polyvinylidene fluoride (PVDF) membrane was purchased from Amersham Pharmacia Biotech Inc., Piscataway, NJ, USA. All other agents used in this study were of a reagent grade.

\subsection{Antioxidant Capability Measurement}

\subsubsection{Reducing Power Assay}

The reducing power of CAE was measured using a slightly modified version of a previously described method [50]. Briefly, various concentrations of CAE $(5-500 \mu \mathrm{g} / \mathrm{mL})$ in $0.2 \mathrm{M}$ PBS containing $1 \%$ ferrocyanate were prepared and then incubated for $20 \mathrm{~min}$. Subsequently, the mixture was centrifuged after the addition of $10 \%$ TCA. The absorbance was measured at $700 \mathrm{~nm}$ after $1 \%$ ferric chloride solution was mixed with the supernatant. The absorbance intensity served as a proxy measure for the reducing power of the extract, as follows:

$$
\text { Reducing power }(\%)=\left(\frac{A_{\text {control at } 700 \mathrm{~nm}}-A_{\text {sample at }} 700 \mathrm{~nm}}{A_{\text {control at } 700 \mathrm{~nm}}}\right) \times 100
$$

\subsubsection{Ferrous Ion Chelating Activity}

The chelating of ferrous ions by CAE was assayed using a slightly modified version of the ferrozine assay employed in a previous study [50,51]. Briefly, 50-500 $\mu \mathrm{g} / \mathrm{mL}$ CAE was added to $2 \mathrm{mM}$ $\mathrm{FeCl}_{2}$ solution. After the addition of $5 \mathrm{mM}$ ferrozine, the reaction was initiated. The absorbance was then spectrophotometrically determined at $562 \mathrm{~nm}$ by using a microplate reader (BioTek, Winooski, VT, USA). The results were calculated using the following equation and expressed as the percentage inhibition of the generation of the ferrozine- $\mathrm{Fe}^{2+}$ complex:

$$
\text { Chelating effect }(\%)=\left(\frac{A_{\text {control at } 562 \mathrm{~nm}}-A_{\text {sample at } 562 \mathrm{~nm}}}{A_{\text {control at } 562 \mathrm{~nm}}}\right) \times 100
$$

\subsubsection{Hydroxyl Radical Scavenging Activity Assay}

The capacity of CAE to scavenge hydroxyl radicals was estimated using a slightly modified version of a previously reported method [50,51]. The assay was performed by mixing 10-1000 $\mu \mathrm{g} / \mathrm{mL}$ CAE, $10 \mathrm{mM}$ ascorbic acid, $10 \mathrm{mM}$ deoxyribose, $5 \mathrm{mM} \mathrm{FeCl}_{3}, 1 \mathrm{mM}$ EDTA, $10 \mathrm{mM} \mathrm{H}_{2} \mathrm{O}_{2}, 65 \mu \mathrm{L}$ $\mathrm{KH}_{2} \mathrm{PO}_{4}-\mathrm{KOH}$ buffer, and distilled water, and was then incubated for $15 \mathrm{~min}$ at $100{ }^{\circ} \mathrm{C}$. A pink chromogen was formed and the mixture was centrifuged. Mannitol was used as the positive control. The absorbance of the supernatant was measured at $532 \mathrm{~nm}$ by using a microplate reader (BioTek, Winooski, VT, USA). The scavenging activity of CAE was obtained as the percentage inhibition of deoxyribose degradation, as follows:

$$
\text { Inhibition }(\%)=\left(\frac{A_{\text {control at } 532 \mathrm{~nm}}-A_{\text {sample at } 532 \mathrm{~nm}}}{A_{\text {control at } 532 \mathrm{~nm}}}\right) \times 100
$$

\subsubsection{Determination of Superoxide Anion Scavenging Activity}

The ability of CAE to scavenge superoxide anions was assayed using a modified version of a previously reported model [50]. Reaction mixtures containing $936 \mu \mathrm{M}$ dihydronicotinamide-adenine dinucleotide, $120 \mu \mathrm{M}$ phenazine methosulfate, and $200 \mu \mathrm{M}$ nitroblue tetrazolium were prepared in $0.1 \mathrm{M}$ PBS, and CAE solution $(1-50 \mu \mathrm{g} / \mathrm{mL})$ was added. The mixture was incubated for $5 \mathrm{~min}$. 
The absorbance was determined using an enzyme-linked immunosorbent assay reader (ELISA) (Tecan, Grödig, Austria) at $560 \mathrm{~nm}$.

\subsubsection{Determination of Peroxide Scavenging Activity}

The capability of CAE to scavenge $\mathrm{H}_{2} \mathrm{O}_{2}$ was spectrophotometrically measured by using a method described in a previous study [50,52]. $\mathrm{H}_{2} \mathrm{O}_{2}(20 \mathrm{mM})$ was prepared in PBS and added to various concentrations of CAE (50-1000 $\mu \mathrm{g} / \mathrm{mL})$. The mixture was incubated for $10 \mathrm{~min}$. The absorption was detected using an ELISA reader (Tecan, Grödig, Austria) at $230 \mathrm{~nm}$. The $\mathrm{H}_{2} \mathrm{O}_{2}$ scavenging activity of $\mathrm{CAE}$ was calculated using the following equation:

$$
\text { Scavenging effect }(\%)=\left(\frac{A_{\text {control at } 230 \mathrm{~nm}}-A_{\text {sample at } 230 \mathrm{~nm}}}{A_{\text {control at } 230 \mathrm{~nm}}}\right) \times 100
$$

\subsection{Cell Culture and UV Exposure}

Hs68 cells were cultured and exposed to UV irradiation as previously described [53]. Cells were incubated in DMEM without serum in the presence of CAE for $24 \mathrm{~h}$ after UVB irradiation. A UV lighter (peak emission was $302 \mathrm{~nm}, \mathrm{CL}-1000 \mathrm{M}$, UVP, Upland, CA, USA) was used for UVB exposure. UVB irradiation doses were $40-80 \mathrm{~mJ} / \mathrm{cm}^{2}$ (exposure time was $15-30 \mathrm{~s}$ ) [32,54].

\subsection{Antioxidant Activity of CAE in Human Skin Fibroblasts}

\subsubsection{Fluorescence Assay for Intracellular ROS in Fibroblasts}

The fluorescence assay was performed using a slightly modified version of a previously described method [55]. Fibroblasts were planted for $24 \mathrm{~h}$ and then exposed to UVB light. The UVB irradiation dose was $80 \mathrm{~mJ} / \mathrm{cm}^{2}$ (approximately $30 \mathrm{~s}$ ). After incubation with CAE $(1-50 \mu \mathrm{g} / \mathrm{mL}$ ) for $2 \mathrm{~h}$, the cells were incubated with $10 \mu \mathrm{M}$ DCFDA in DMEM for $30 \mathrm{~min}$. A fluorescence microscope was used to observe the images (Leica DMIL, Wetzlar, Germany), and the fluorescence (emission wavelength was $520 \mathrm{~nm}$ and excitation wavelength was $488 \mathrm{~nm}$ ) was detected using an ELISA reader (Thermo Electron Corporation, Vantaa, Finland).

$$
\text { Relative fluorescence }(\%)=\left(\frac{A_{\text {control }}-A_{\text {sample }}}{A_{\text {control }}}\right) \times 100
$$

\subsubsection{Catalase Activity Assay}

Cells were incubated with CAE $(5-50 \mu \mathrm{g} / \mathrm{mL})$ for $24 \mathrm{~h}$ after UVB irradiation. Cells were harvested and centrifuged $\left(1000 \times g\right.$ at $4{ }^{\circ} \mathrm{C}$ for $\left.10 \mathrm{~min}\right)$. The cell pellet was homogenized in $1 \mathrm{~mL}$ cold buffer (50 mM phosphate containing $1 \mathrm{mM}$ EDTA, pH 6-7). The CAT content in the supernatant was measured using a CAT assay kit (Cayman Chemical Company, Ann Arbor, MI, USA). Briefly, $20 \mu \mathrm{L}$ of the sample, $30 \mu \mathrm{L}$ of methanol, and $100 \mu \mathrm{L}$ of CAT assay buffer were added to a microplate, and the mixture was incubated on the plate in the dark on an orbital shaker for $20 \mathrm{~min}$. Thirty $\mu \mathrm{L}$ of potassium hydroxide was added to terminate the reaction and the chromogen system, and a microplate reader (Tecan, Grödig, Austria) was used to measure the absorbance at $540 \mathrm{~nm}$.

\subsection{Immunoblot Analysis}

Cells were incubated with CAE $(5-50 \mu \mathrm{g} / \mathrm{mL})$ for $24 \mathrm{~h}$ after UVB irradiation. Cells were collected and homogenized with lysis buffer as described in previous studies [53,54]. Equal protein amounts $(30 \mu \mathrm{g})$ were loaded and separated on sodium dodecyl sulfate polyacrylamide gels and then transferred to a PVDF membrane. The membrane was incubated with specific antibodies, which comprised antibodies against IкB, p-IкB, and COX-2 (Santa Cruz Biotechnology, Inc., Santa Cruz, CA, USA). The blots were then incubated with antiimmunoglobulin G-horseradish peroxidase, and the ECL ${ }^{\mathrm{TM}}$ 
detection reagent (Amersham Biosciences, Buckinghamshire, UK) was added. Immunoreactive proteins were detected using an ECL Western blotting detection system (LAS-4000, Fujifilm, Tokyo, Japan), and density of bands was determined using a densitometric program (Multi Gauge V2.2, Fujifilm, Tokyo, Japan).

\subsection{Immunofluorescence Staining}

Cells were cultivated on glass cover slips as described in a previous paper [53]. After UVB exposure, various concentrations of CAE $(5-25 \mu \mathrm{g} / \mathrm{mL})$ were added and incubated for $24 \mathrm{~h}$. The cells were then immersed in $4 \%$ paraformaldehyde and incubated with nonfat milk containing Triton X-100. A primary antibody was added to the cells, and the cells were then incubated with an Alexa Fluor 488 antirabbit IgG secondary antibody (Invitrogen, Carlsbad, CA, USA). The cells were washed with PBS buffer to rinse off the unbound secondary antibody. Finally, the samples were counterstained with the ProLong ${ }^{\circledR}$ Gold antifade reagent and viewed using a microscope (Leica DMIL, Wetzlar, Germany).

\subsection{Antiphotoaging Activity of CAE in the Hairless Mouse Skin}

\subsubsection{Animals}

Five-week-old BALB/cAnN.Cg-Foxn1 ${ }^{\text {nu }} /$ CrlNarl hairless female mice were obtained from the National Laboratory Animal Center in Taiwan. Animals were housed in individually controlled, ventilated caging systems with a relative humidity $(50 \% \pm 10 \%)$, controlled temperature $\left(22 \pm 2{ }^{\circ} \mathrm{C}\right)$, and 12-h light/dark cycle. The experimental protocols (100-124-N) were approved by the Institutional Animal Use and Care Committee of China Medical University (28 December 2010).

\subsubsection{UVB Irradiation and Topical Application of CAE}

The hairless mice were randomly divided into five groups (six animals in each group): control, UVB treated, UVB treated with $50 \mu \mathrm{L}$ vehicle, UVB exposed with $100 \mu \mathrm{g} / \mathrm{mL}$ CAE, and UVB exposed with $200 \mu \mathrm{g} / \mathrm{mL}$ CAE. The hairless mice in the UVB-exposed group were irradiated for 10 weeks on the dorsal skin, and the UV dose was similar to that described in a previous study $[26,54]$. In the vehicle group, $50 \mu \mathrm{L}$ of glycerol was topically applied on the dorsal skin of the mice every day, and in the CAE group, glycerol containing 100 or $200 \mu \mathrm{g} / \mathrm{mL}$ CAE was applied every day. At the end of the 10-week experiment, the mice were sacrificed by an overdose of $\mathrm{CO}_{2}$. The dorsal skin specimens were immersed in formaldehyde. The skin slides were stained with Masson's trichrome or hematoxylin and eosin, mounted on a coverslip, and observed under an optical microscope.

\subsubsection{Immunohistological Analysis of MMP-1, IL-6, and NF- $\mathrm{kB}$}

The sections of the hairless mouse skin were incubated with primary antibodies against MMP-1, IL-6, and NF-KB overnight. The sections were incubated with the secondary antibody after washing. The results were visualized under an optical microscope.

\subsection{Statistical Analysis}

All results are presented as the mean \pm standard deviation of at least three independent experiments. $p<0.05$ was considered statistically significant, and one-way analysis of variance, followed by a Scheffe's test, was used to analyze the results.

\section{Conclusions}

In this study, CAE exhibited potent antioxidant activity, including a high reducing capability, free radical scavenging capability, and high metal chelating activity, ameliorating UVB-induced ROS and enhancing CAT activity in human skin fibroblasts. In addition, CAE exhibited antiinflammatory activity, inhibited UVB-induced COX-2 and $p$-IкB expression, and suppressed NF- $\mathrm{KB}$ translocation to the nucleus (Figure 21). Finally, CAE reduced UVB-induced skin erythema and thickness, as well 
as increased the collagen content of the dermis in hairless mice. The results suggest that CAE can be useful for ameliorating aging- and photoaging-related disorders because of its antioxidant and antiinflammatory properties.

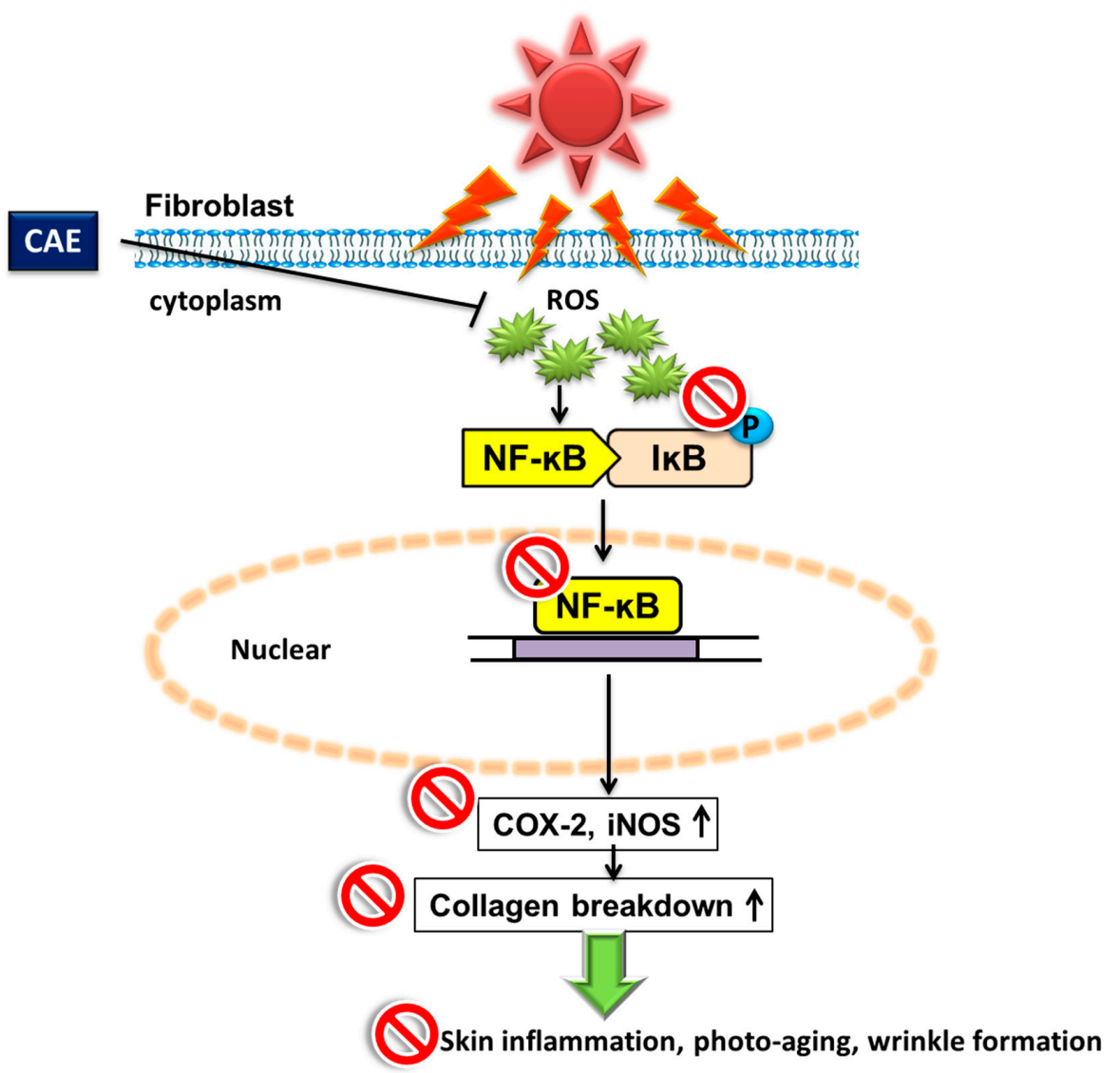

Figure 21. Scheme of CAE inhibition of UVB-induced inflammation and photodamage. ( $\uparrow$ : upregulation; inhibition; red circles: inhibition)

Acknowledgments: This study was sponsored by China Medical University (CMU102-ASIA-18, CMU103-ASIA-11), Taichung, and the Ministry of Science and Technology (MOST 104-2320-B-039-006), Taipei, Taiwan.

Author Contributions: Po-Yuan Wu, Chi-Chang Huang, Kuo-Ching Wen and Hsiu-Mei Chiang conceived the study and participated in its design and coordination; Yin Chu, Ya-Han Huang and Yu-Han Liu performed the cell culture and experiments and analyzed the data; Yin Chu, Ping Lin and Hsiu-Mei Chiang performed the animal experiments and collected the data; and Po-Yuan Wu, Chi-Chang Huang, Kuo-Ching Wen, Chien-Yih Lin, Mei-Chich Hsu, and Hsiu-Mei Chiang wrote and revised the paper.

Conflicts of Interest: The authors state no conflicts of interest.

\section{Abbreviations}

BHT Dibutyl hydroxy toluene

CAE Coffea arabica extract

CAT Catalase

DCFDA $\quad 2^{\prime}, 7^{\prime}$-dichlorofluorescin diacetate

DMEM Dulbecco's modified Eagle's medium

FBS Fetal bovine serum

IL-6 Interleukin 6

NF-kB Nuclear factor-kappa B

ROS Reactive oxygen species

UV Ultraviolet 


\section{References}

1. Kerzendorfer, C.; O'Driscoll, M. Uvb and caffeine: Inhibiting the DNA damage response to protect against the adverse effects of UVB. J. Investig. Dermatol. 2009, 129, 1611-1613. [CrossRef] [PubMed]

2. Rittie, L.; Fisher, G.J. UV-light-induced signal cascades and skin aging. Ageing Res. Rev. 2002, 1, 705-720. [CrossRef]

3. Sanches Silveira, J.E.; Myaki Pedroso, D.M. UV light and skin aging. Environ. Health 2014, 29, $243-254$. [CrossRef] [PubMed]

4. D'Orazio, J.; Jarrett, S.; Amaro-Ortiz, A.; Scott, T. UV radiation and the skin. Int. J. Mol. Sci. 2013, 14, 12222-12248. [CrossRef] [PubMed]

5. Gelse, K.; Poschl, E.; Aigner, T. Collagens—Structure, function, and biosynthesis. Adv. Drug Deliv. Rev. 2003, 55, 1531-1546. [CrossRef] [PubMed]

6. Deliconstantinos, G.; Villiotou, V.; Stavrides, J.C. Increase of particulate nitric oxide synthase activity and peroxynitrite synthesis in UVB-irradiated keratinocyte membranes. Biochem. J. 1996, 320 Pt 3, 997-1003. [CrossRef] [PubMed]

7. Jung, S.K.; Ha, S.J.; Kim, Y.A.; Lee, J.; Lim, T.G.; Kim, Y.T.; Lee, N.H.; Park, J.S.; Yeom, M.H.; Lee, H.J.; et al. MLK3 is a novel target of dehydroglyasperin D for the reduction in UVB-induced COX-2 expression in vitro and in vivo. J. Cell. Mol. Med. 2015, 19, 135-142. [CrossRef] [PubMed]

8. Rhodes, L.E.; Gledhill, K.; Masoodi, M.; Haylett, A.K.; Brownrigg, M.; Thody, A.J.; Tobin, D.J.; Nicolaou, A. The sunburn response in human skin is characterized by sequential eicosanoid profiles that may mediate its early and late phases. FASEB J. 2009, 23, 3947-3956. [CrossRef] [PubMed]

9. Wu, N.L.; Fang, J.Y.; Chen, M.; Wu, C.J.; Huang, C.C.; Hung, C.F. Chrysin protects epidermal keratinocytes from UVA- and UVB-induced damage. J. Agric. Food Chem. 2011, 59, 8391-8400. [CrossRef] [PubMed]

10. Rodrigues, K.C.; Chibli, L.A.; Santos, B.C.; Temponi, V.S.; Pinto, N.C.; Scio, E.; Del-Vechio-Vieira, G.; Alves, M.S.; Sousa, O.V. Evidence of bioactive compounds from vernonia polyanthes leaves with topical anti-inflammatory potential. Int. J. Mol. Sci. 2016, 17, 1929. [CrossRef] [PubMed]

11. Choi, Y.J.; Moon, K.M.; Chung, K.W.; Jeong, J.W.; Park, D.; Kim, D.H.; Yu, B.P.; Chung, H.Y. The underlying mechanism of proinflammatory NF-kB activation by the mTORC2/Akt/IKK $\alpha$ pathway during skin aging. Oncotarget 2016, 7, 52685. [CrossRef] [PubMed]

12. Cooper, S.J.; Bowden, G.T. Ultraviolet b regulation of transcription factor families: Roles of nuclear factor-kappa B (NF-kB) and activator protein-1 (AP-1) in UVB-induced skin carcinogenesis. Curr. Cancer Drug Targets 2007, 7, 325-334. [CrossRef] [PubMed]

13. Bond, M.; Baker, A.H.; Newby, A.C. Nuclear factor $\kappa B$ activity is essential for matrix metalloproteinase- 1 and -3 upregulation in rabbit dermal fibroblasts. Biochem. Biophys. Res. Commun. 1999, 264, 561-567. [CrossRef] [PubMed]

14. Halliday, G.M. Inflammation, gene mutation and photoimmunosuppression in response to uvr-induced oxidative damage contributes to photocarcinogenesis. Mutat. Res. 2005, 571, 107-120. [CrossRef] [PubMed]

15. Surowiak, P.; Gansukh, T.; Donizy, P.; Halon, A.; Rybak, Z. Increase in cyclooxygenase-2 (COX-2) expression in keratinocytes and dermal fibroblasts in photoaged skin. J. Cosmet. Dermatol. 2014, 13, 195-201. [CrossRef] [PubMed]

16. Johnson, E.J. Role of lutein and zeaxanthin in visual and cognitive function throughout the lifespan. Nutr. Rev. 2014, 72, 605-612. [CrossRef] [PubMed]

17. Peng, C.; Wang, X.; Chen, J.; Jiao, R.; Wang, L.; Li, Y.M.; Zuo, Y.; Liu, Y.; Lei, L.; Ma, K.Y.; et al. Biology of ageing and role of dietary antioxidants. BioMed Res. Int. 2014, 2014, 831841. [CrossRef] [PubMed]

18. Saewan, N.; Jimtaisong, A. Natural products as photoprotection. J. Cosmet. Dermatol. 2015, 14, 47-63. [CrossRef] [PubMed]

19. Giampieri, F.; Alvarez-Suarez, J.M.; Tulipani, S.; Gonzales-Paramas, A.M.; Santos-Buelga, C.; Bompadre, S.; Quiles, J.L.; Mezzetti, B.; Battino, M. Photoprotective potential of strawberry (Fragaria $\times$ ananassa) extract against UV-A irradiation damage on human fibroblasts. J. Agric. Food Chem. 2012, 60, 2322-2327. [CrossRef] [PubMed]

20. Feng, X.X.; Yu, X.T.; Li, W.J.; Kong, S.Z.; Liu, Y.H.; Zhang, X.; Xian, Y.F.; Zhang, X.J.; Su, Z.R.; Lin, Z.X. Effects of topical application of patchouli alcohol on the UV-induced skin photoaging in mice. Eur. J. Pharm. Sci. 2014, 63, 113-123. [CrossRef] [PubMed] 
21. Kang, T.H.; Park, H.M.; Kim, Y.B.; Kim, H.; Kim, N.; Do, J.H.; Kang, C.; Cho, Y.; Kim, S.Y. Effects of red ginseng extract on UVB irradiation-induced skin aging in hairless mice. J. Ethnopharmacol. 2009, 123, 446-451. [CrossRef] [PubMed]

22. Ahsan, H.; Reagan-Shaw, S.; Eggert, D.M.; Tan, T.C.; Afaq, F.; Mukhtar, H.; Ahmad, N. Protective effect of sanguinarine on ultraviolet B-mediated damages in SKH-1 hairless mouse skin: Implications for prevention of skin cancer. Photochem. Photobiol. 2007, 83, 986-993. [CrossRef] [PubMed]

23. Chen, C.C.; Chiang, A.N.; Liu, H.N.; Chang, Y.T. EGb-761 prevents ultraviolet B-induced photoaging via inactivation of mitogen-activated protein kinases and proinflammatory cytokine expression. J. Dermatol. Sci. 2014, 75, 55-62. [CrossRef] [PubMed]

24. Conney, A.H.; Lou, Y.R.; Nghiem, P.; Bernard, J.J.; Wagner, G.C.; Lu, Y.P. Inhibition of UVB-induced nonmelanoma skin cancer: A path from tea to caffeine to exercise to decreased tissue fat. Top. Curr. Chem. 2013, 329, 61-72. [PubMed]

25. Hou, H.; Li, B.; Zhang, Z.; Xue, C.; Yu, G.; Wang, J.; Bao, Y.; Bu, L.; Sun, J.; Peng, Z.; et al. Moisture absorption and retention properties, and activity in alleviating skin photodamage of collagen polypeptide from marine fish skin. Food Chem. 2012, 135, 1432-1439. [CrossRef] [PubMed]

26. Kuo, Y.H.; Lin, T.Y.; You, Y.J.; Wen, K.C.; Sung, P.J.; Chiang, H.M. Antiinflammatory and antiphotodamaging effects of ergostatrien-3 $\beta$-ol, isolated from Antrodia camphorata, on hairless mouse skin. Molecules 2016, 21, 1213. [CrossRef] [PubMed]

27. Andersen, L.F.; Jacobs, D.R., Jr.; Carlsen, M.H.; Blomhoff, R. Consumption of coffee is associated with reduced risk of death attributed to inflammatory and cardiovascular diseases in the iowa women's health study. Am. J. Clin. Nutr. 2006, 83, 1039-1046. [PubMed]

28. Higdon, J.V.; Frei, B. Coffee and health: A review of recent human research. Crit. Rev. Food Sci. Nutr. 2006, 46, 101-123. [CrossRef] [PubMed]

29. Gulcin, I. Antioxidant activity of food constituents: An overview. Arch. Toxicol. 2012, 86, 345-391. [CrossRef] [PubMed]

30. Kim, A.R.; Zou, Y.; Kim, H.S.; Choi, J.S.; Chang, G.Y.; Kim, Y.J.; Chung, H.Y. Selective peroxynitrite scavenging activity of 3-methyl-1,2-cyclopentanedione from coffee extract. J. Pharm. Pharmacol. 2002, 54, 1385-1392. [CrossRef] [PubMed]

31. Farris, P. Idebenone, green tea, and coffeeberry extract: New and innovative antioxidants. Dermatol. Ther. 2007, 20, 322-329. [CrossRef] [PubMed]

32. Chiang, H.M.; Lin, T.J.; Chiu, C.Y.; Chang, C.W.; Hsu, K.C.; Fan, P.C.; Wen, K.C. Coffea arabica extract and its constituents prevent photoaging by suppressing mmps expression and map kinase pathway. Food Chem. Toxicol. 2011, 49, 309-318. [CrossRef] [PubMed]

33. Bae, J.S.; Han, M.; Shin, H.S.; Kim, M.K.; Shin, C.Y.; Lee, D.H.; Chung, J.H. Perilla frutescens leaves extract ameliorates ultraviolet radiation-induced extracellular matrix damage in human dermal fibroblasts and hairless mice skin. J. Ethnopharmacol. 2017, 195, 334-342. [CrossRef] [PubMed]

34. Posmyk, M.M.; Bailly, C.; Szafranska, K.; Janas, K.M.; Corbineau, F. Antioxidant enzymes and isoflavonoids in chilled soybean (Glycine max (L.) Merr.) seedlings. J. Plant Physiol. 2005, 162, 403-412. [CrossRef] [PubMed]

35. Hung, C.F.; Fang, C.L.; Al-Suwayeh, S.A.; Yang, S.Y.; Fang, J.Y. Evaluation of drug and sunscreen permeation via skin irradiated with UVA and UVB: Comparisons of normal skin and chronologically aged skin. J. Dermatol. Sci. 2012, 68, 135-148. [CrossRef] [PubMed]

36. Taheri, A.; Sabeena Farvin, K.H.; Jacobsen, C.; Baron, C.P. Antioxidant activities and functional properties of protein and peptide fractions isolated from salted herring brine. Food Chem. 2014, 142, 318-326. [CrossRef] [PubMed]

37. Roginsky, V. Chain-breaking antioxidant activity of natural polyphenols as determined during the chain oxidation of methyl linoleate in Triton X-100 micelles. Arch. Biochem. Biophys. 2003, 414, 261-270. [CrossRef]

38. Durak, A.; Gawlik-Dziki, U.; Kowlska, I. Coffee with ginger-Interactions of biologically active phytochemicals in the model system. Food Chem. 2015, 166, 261-269. [CrossRef] [PubMed]

39. Godic, A.; Poljsak, B.; Adamic, M.; Dahmane, R. The role of antioxidants in skin cancer prevention and treatment. Oxid. Med. Cell. Longev. 2014, 2014, 860479. [CrossRef] [PubMed]

40. Chen, L.; Hu, J.Y.; Wang, S.Q. The role of antioxidants in photoprotection: A critical review. J. Am. Acad. Dermatol. 2012, 67, 1013-1024. [CrossRef] [PubMed] 
41. Choi, H.S.; Park, E.D.; Park, Y.; Han, S.H.; Hong, K.B.; Suh, H.J. Topical application of spent coffee ground extracts protects skin from ultraviolet B-induced photoaging in hairless mice. Photochem. Photobiol. Sci. 2016, 15, 779-790. [CrossRef] [PubMed]

42. Kim, M.S.; Oh, G.H.; Kim, M.J.; Hwang, J.K. Fucosterol inhibits matrix metalloproteinase expression and promotes type-1 procollagen production in UVB-induced hacat cells. Photochem. Photobiol. 2013, 89, 911-918. [CrossRef] [PubMed]

43. Zhan, J.Y.; Wang, X.F.; Liu, Y.H.; Zhang, Z.B.; Wang, L.; Chen, J.N.; Huang, S.; Zeng, H.F.; Lai, X.P. Andrographolide sodium bisulfate prevents UV-induced skin photoaging through inhibiting oxidative stress and inflammation. Mediators Inflamm. 2016, 2016, 3271451. [CrossRef] [PubMed]

44. Pratheeshkumar, P.; Son, Y.O.; Wang, X.; Divya, S.P.; Joseph, B.; Hitron, J.A.; Wang, L.; Kim, D.; Yin, Y.; Roy, R.V.; et al. Cyanidin-3-glucoside inhibits UVB-induced oxidative damage and inflammation by regulating map kinase and NF-kB signaling pathways in SKH-1 hairless mice skin. Toxicol. Appl. Pharmacol. 2014, 280, 127-137. [CrossRef] [PubMed]

45. Indra, M.R.; Karyono, S.; Ratnawati, R.; Malik, S.G. Quercetin suppresses inflammation by reducing ERK1/2 phosphorylation and NF $\mathrm{KB}$ activation in leptin-induced human umbilical vein endothelial cells (HUVECs). BMC Res. Notes 2013, 6, 275. [CrossRef] [PubMed]

46. Ranheim, T.; Halvorsen, B. Coffee consumption and human health-Beneficial or detrimental-Mechanisms for effects of coffee consumption on different risk factors for cardiovascular disease and type 2 diabetes mellitus. Mol. Nutr. Food Res. 2005, 49, 274-284. [CrossRef] [PubMed]

47. Preedy, V. Coffee in Health and Disease Prevention; Academic Press: London, UK, 2014.

48. Cichocki, M.; Blumczynska, J.; Baer-Dubowska, W. Naturally occurring phenolic acids inhibit 12-O-tetradecanoylphorbol-13-acetate induced NF- $\mathrm{kB}$, iNOS and COX-2 activation in mouse epidermis. Toxicology 2010, 268, 118-124. [CrossRef] [PubMed]

49. Yan, C.H.; Chen, X.G.; Li, Y.; Han, R. Effects of genistein, a soybean-derived isoflavone, on proliferation and differentiation of B16-Bl6 mouse melanoma cells. J. Asian Nat. Prod. Res. 1999, 1, 285-299. [CrossRef] [PubMed]

50. Chiang, H.-M.; Chiu, H.-H.; Liao, S.-T.; Chen, Y.-T.; Chang, H.-C.; Wen, K.-C. Isoflavonoid-rich flemingia macrophylla extract attenuates UVB-induced skin damage by scavenging reactive oxygen species and inhibiting MAP kinase and MMP expression. Evid. Based Complement. Altern. Med. 2013, 2013, 696879. [CrossRef] [PubMed]

51. Wen, K.C.; Chiu, H.H.; Fan, P.C.; Chen, C.W.; Wu, S.M.; Chang, J.H.; Chiang, H.M. Antioxidant activity of ixora parviflora in a cell/cell-free system and in UV-exposed human fibroblasts. Molecules 2011, 16, 5735-5752. [CrossRef] [PubMed]

52. Chiang, H.-M.; Chen, H.-C.; Chiu, H.-H.; Chen, C.-W.; Wang, S.-M.; Wen, K.-C. Neonauclea reticulata (havil.) merr stimulates skin regeneration after UVB exposure via ROS scavenging and modulation of the MAPK/MMPs/collagen pathway. Evid. Based Complement. Altern. Med. 2013, 2013, 324864. [CrossRef] [PubMed]

53. Chiang, H.M.; Chan, S.Y.; Chu, Y.; Wen, K.C. Fisetin ameliorated photodamage by suppressing the mitogen-activated protein kinase/matrix metalloproteinase pathway and nuclear factor- $\mathrm{kB}$ pathways. J. Agric. Food Chem. 2015, 63, 4551-4560. [CrossRef] [PubMed]

54. Kuo, Y.H.; Chen, C.W.; Chu, Y.; Lin, P.; Chiang, H.M. In vitro and in vivo studies on protective action of $\mathrm{N}$-phenethyl caffeamide against photodamage of skin. PLoS ONE 2015, 10, e0136777. [CrossRef] [PubMed]

55. Chiang, H.M.; Chen, C.W.; Lin, T.Y.; Kuo, Y.H. N-phenethyl caffeamide and photodamage: Protecting skin by inhibiting type I procollagen degradation and stimulating collagen synthesis. Food Chem. Toxicol. 2014, 72C, 154-161. [CrossRef] [PubMed]

(C) 2017 by the authors. Licensee MDPI, Basel, Switzerland. This article is an open access article distributed under the terms and conditions of the Creative Commons Attribution (CC BY) license (http:/ / creativecommons.org/licenses/by/4.0/). 